\title{
Professores/as: multiplicadores/as de educação em direitos humanos
}

\author{
Vera Maria Candau \\ Doutora em Educação, pela Universidad Complutense de Madrid. \\ Professora da Pontifícia Universidade Católica do Rio de Janeiro, \\ Rio de Janeiro, Rio de Janeiro, Brasil \\ r.sousalima@uol.com.br
}

Resumo Os direitos humanos constituem um dos eixos centrais da problemática das sociedades contemporâneas. Para afirmá-los, a educação em direitos humanos vem desenvolvendo-se cada vez com maior força no Brasil, tanto do ponto de vista normativo como das políticas públicas e das atividades promovidas pelas organizações da sociedade civil. No entanto, é possível constatar que ainda são frágeis e pouco frequentes a discussão e a reflexão sobre o sentido da educação em direitos humanos nas nossas instituições de ensino. O presente trabalho defende a tese de que a formação continuada de professores/as constitui um espaço privilegiado para a incorporação da educação em direitos humanos nas nossas escolas, assim como para a formação de educadores/as como agentes multiplicadores comprometidos com os direitos humanos no âmbito educacional e na sociedade em geral. Está estruturado em três partes, que abordam os seguintes aspectos: o sentido da educação em direitos humanos, a concepção de formação continuada adotada e as principais características que deve ter para que mobilize a formação de professores/as multiplicadores/as da educação em direitos humanos.

Palavras-chave: Brasil, educação, educação em direitos humanos, formação continuada de professores, multiplicadores.

\section{Introdução}

耳 ste ano estamos comemorando 65 anos da Declaração Universal - dos Direitos Humanos e 20 anos da II Conferência Mundial sobre os Direitos Humanos, promovida pela Organização das Nações Unidas para comemorar os 45 anos da Declaração Universal, realizada em Viena em 1993. Foram/são anos de muitas controvérsias, novos contextos, mudanças aceleradas, em que se multiplicaram e diversificaram as violações de direitos humanos e, ao mesmo tempo, as lutas e esforços pela afirmação dos direitos já definidos e pela construção e reconhecimento de novos direitos.

Os direitos humanos continuam sendo um dos eixos fundamentais da problemática das sociedades contemporâneas. Do âmbito planetário ao local, afirmados ou negados, exaltados ou violados, eles fazem parte da nossa vida individual, comunitária e coletiva.

Segundo Lynn Hunt (2009, p. 24-25),

os direitos humanos são difíceis de determinar porque sua definição, e na verdade sua própria existência, dependem tanto das emoções quanto da razão. A reivindicação de autoevidência se baseia em última análise num apelo emocional: ela é convincente se ressoa dentro de cada indivíduo. 
Além disso, temos muita certeza de que um direito humano está em questão quando nos sentimos horrorizados pela sua violação.

No plano nacional, a partir da Constituição de 1988, o Estado brasileiro tem feito um esforço sistemático orientado para a promoção, defesa e proteção dos direitos fundamentais e, respondendo em muitas ocasiões às demandas de diferentes movimentos sociais, vem ampliando progressivamente a inclusão de novas dimensões e questões em suas preocupações. Hoje possuímos um significativo conjunto normativo e de políticas públicas centradas na proteção e promoção dos direitos humanos.

Por outro lado, a educação em direitos humanos vem se afirmando cada vez com maior força no Brasil, tanto no âmbito das políticas públicas como das organizações da sociedade civil, especialmente a partir do lançamento do Plano Nacional de Educação em Direitos Humanos em 2003, e de sua reedição em 2006 (Brasil, 2003, 2006). Recentemente, em 2012, foram aprovadas pelo Conselho Nacional de Educação e homologadas pelo Ministro da Educação, as Diretrizes Nacionais para a Educação em Direitos Humanos (Resolução CNE/CP n. 1), publicadas no Diário Oficial da União em 30 de maio de 2012 (Brasil, 2012).

Tanto a Secretaria de Direitos Humanos quanto o Ministério de Educação vêm promovendo atividades e oferecendo apoios diversos para o seu desenvolvimento. São realizados seminários, cursos, palestras, fóruns, e publicados livros, artigos e materiais didáticos etc. em diferentes regiões do país, por iniciativa de universidades, secretarias de Educação e outros órgãos públicos, movimentos sociais, organizações não governamentais etc.

No entanto, considero que, para que os referidos documentos afetem realmente as práticas educativas de nossas escolas, a formação - inicial e continuada - de professores e professoras sobre essa temática é fundamental. A partir da experiência de desenvolver diferentes atividades de educação em direitos humanos, participar em vários espaços em que se reflete e discute essa temática, assim como do diálogo com educadores/as de diversas partes do país, posso afirmar que são poucas as instituições, tanto do ensino básico quanto do ensino superior, que introduzem de modo sistemático questões relativas à educação em direitos humanos nos processos formativos que promovem. É possível afirmar que ainda é frágil e pouco frequente a discussão sobre essa incorporação e a reflexão sobre o sentido da educação em direitos humanos nas nossas instituições educativas.

Partindo dessas considerações iniciais, pretendo no presente trabalho defender a tese de que a formação continuada de professores/as constitui um es- paço privilegiado para a afirmação da educação em direitos humanos nas nossas escolas. Os professores e professoras convivem diariamente com crianças e jovens durante muitas horas e muitos anos. Se incorporassem fortemente a perspectiva da educação em direitos humanos, constituiriam agentes multiplicadores de especial importância. Essa é a nossa aposta e o nosso empenho.

Esta reflexão está centrada em três aspectos que considero fundamentais: o sentido da educação em direitos humanos, a concepção de formação continuada que assumo e as principais características que essa educação deve ter para que mobilize a formação de professores/as multiplicadores/as da educação em direitos humanos. Está situada no contexto da pesquisa "Educação em Direitos Humanos na América Latina e no Brasil: gênese histórica e realidade atual", que vem sendo desenvolvida desde 2008, com o apoio do $\mathrm{CNPq}$, pelo Grupo de Estudos sobre Cotidiano, Educação e Cultura/s (GECEC), que coordeno e que está vinculado ao Programa de Pós-graduação em Educação da PUC-Rio.

\section{Que sentido tem educar em direitos humanos?}

Uma questão fundamental para a presente reflexão é perguntarmo-nos sobre a possibilidade e o sentido de educar em direitos humanos.

Em primeiro lugar, é importante ter presente que os direitos humanos são historicamente construídos e não brotam espontaneamente da dinâmica social. São conquistas históricas e frutos de muitas lutas e sofrimentos, que suscitaram uma progressiva tomada de consciência da humanidade sobre o que significa sermos pessoas humanas.

No mundo atual é possível detectar, em muitos ambientes, indicadores de retrocesso dessa consciência, e muitos seres humanos são considerados descartáveis e "sobram", justificando-se a sua eliminação física ou simbólica. Hoje é de especial importância promover processos em que se trabalhe a sensibilização, a consciência da dignidade de todo ser humano e a promoção de uma cultura dos direitos humanos.

Outro aspecto importante a considerar é a intrínseca relação entre a educação como direito humano e a educação em direitos humanos. Segundo o Programa Mundial para Educação em Direitos $\mathrm{Hu}-$ manos, aprovado pela ONU em 2008,

de um modo geral, a educação em direitos humanos é considerada como parte integrante do direito à educação. Como afirmou o Comitê dos Direitos das Crianças na sua observação geral n.1, "A educação a 
que tem direito toda criança é a que tem por objeto prepará-la para a vida cotidiana, fortalecer sua capacidade de desfrutar de todos os direitos humanos e fomentar uma cultura em que prevaleçam valores de direitos humanos apropriados" (parte 2). Esta educação oferece a toda criança uma ferramenta indispensável para que, com seu esforço, logre ao longo da sua vida uma resposta equilibrada e respeitosa dos direitos humanos às dificuldades que acompanham a um período de mudança fundamental impulsionado pela mundialização, as novas tecnologias e os fenômenos conexos. (p. 8)

Um terceiro argumento que fundamenta a importância da educação em direitos humanos refere-se ao fato de ela ser indispensável para a efetivação de todos os direitos humanos na nossa sociedade.

Para Fritzsche (2004, p. 162), professor de Ciência Política responsável pela cátedra da Unesco sobre educação em direitos humanos na Universidade de Magdeburg (Alemanha), a educação em direitos humanos

não é um adendo pedagógico, mas um componente genuíno dos direitos humanos. Para que serve ter direitos humanos se não os conhecemos e para que conhecê-los se não os compreendemos? E, finalmente, para que serve compreendê-los se ninguém está preparado para respeitá-los e promovê-los? O desenvolvimento dos direitos humanos inclui a compreensão de que eles devem alicerçar-se solidamente na consciência cidadã e que isto exige esforços do movimento conhecido como educação em direitos humanos.

Considero fundamental ressaltar ainda um último motivo para educar-se em direitos humanos. Refere-se à intima relação entre democracia, cidadania e direitos humanos. A formação para o exercício de uma cidadania ativa e a participação nos esforços pela democratização da nossa sociedade, nas suas diferentes dimensões, inclui necessariamente trabalhar a problemática dos direitos humanos.

O horizonte que proponho é favorecer a construção de uma cultura dos direitos humanos que penetre os diferentes espaços da vida social, da família às estruturas e políticas do Estado. Do âmbito local ao planetário.

Essa perspectiva supõe uma concepção de educação que, me atrevo a afirmar, questiona a lógica predominante nas atuais políticas educacionais privilegiadas, centradas quase exclusivamente na aquisição de determinados conteúdos curriculares, no desempenho medido por instrumentos padronizados e na homogeneização dos processos educativos, e orientadas basicamente para a inserção no mercado e na lógica do consumo. A educação em direitos humanos que proponho supõe processos multidimensionais e diversificados, orientados para a construção de sujeitos de direito, cidadãos e cidadãs participativos e comprometidos com a construção democrática em todos os âmbitos sociais.

\section{Como concebemos a formação continuada de professores/as?}

A problemática da formação continuada de professores/as adquire no momento atual especial relevância e destaque. A busca pela construção da qualidade de ensino, especialmente do ensino básico, por mais ambivalente e polissêmica que essa expressão seja, exige necessariamente repensar a formação de professores/as, tanto no que se refere à formação inicial como à formação continuada.

Para a implantação de qualquer proposta que objetive uma renovação das escolas e das práticas pedagógicas, a formação continuada de professores e professoras passa a ser um aspecto especialmente crítico e importante. Qualquer possibilidade de êxito do processo que se pretenda mobilizar tem no/a professor/a em exercício seu principal agente. Nesse sentido, a formação continuada constitui, sem dúvida, um tema de particular atualidade, de natureza complexa e que pode ser abordado e analisado a partir de diferentes enfoques, dimensões e estratégias.

Em confronto com uma perspectiva que centra a formação continuada dos professores/as em processos de capacitação, presenciais ou a distância - as ofertas on line se multiplicam -, orientados a atualizar e "reciclar" os conhecimentos e as práticas dos/as educadores/as, certamente a perspectiva atualmente mais desenvolvida, vem se configurando, principalmente nos últimos tempos, em uma série de buscas, reflexões e pesquisas que não negam as contribuições desses "cursos", mas estão orientadas a construir uma concepção diferente da formação continuada.

$\mathrm{Na}$ experiência de professores e professoras, o dia a dia na escola é um lócus de formação. Nesse cotidiano, ele/a aprende, desaprende, reestrutura o aprendido, faz descobertas e, portanto, é nesse lócus que muitas vezes vai aprimorando a sua formação, particularmente quando são favorecidos os processos coletivos de discussão, a reflexão e as buscas de aperfeiçoamento das práticas educativas. Nesse sentido, considerar a escola como lócus de formação continuada passa a ser uma afirmação fundamental para construir uma nova perspectiva para a formação continuada de professores/as que não se limite a oferecer diferentes "cursos" aos docentes, considerados individualmente. Mas esse objetivo não se alcança de uma maneira espontânea, pois não é o simples fato de estar na escola e de de- 
senvolver uma prática escolar concreta que garante a presença das condições mobilizadoras de um processo formativo. Uma prática repetitiva, uma prática mecânica não favorece esse processo. Para que ele se dê, é importante que essa prática seja reflexiva, capaz de identificar as questões presentes na sala de aula, de buscar formas de trabalhá-las e compreendê-las, conjuntamente. A prática coletiva, construída por grupos de professores/as ou por todo o corpo docente de uma determinada instituição escolar, constitui um elemento-chave particularmente importante.

Nessa perspectiva, o educador português Antônio Nóvoa já em 1991, afirmava:

A formação continuada deve estar articulada com o desempenho profissional dos professores, tornando as escolas como lugares de referência. Trata-se de um objetivo que só adquire credibilidade se os programas de formação se estruturarem em torno de problemas e de projetos de ação e não em torno de conteúdos acadêmicos. (Nóvoa, 1991, p. 30)

\section{E se perguntava:}

Que potencialidades formadoras pode conter um projeto de escola? Como é que a formação pode intervir na promoção e desenvolvimento de práticas inovadoras? Que condições é preciso reunir para que a ação profissional cotidiana possa ser explorada em todas as suas dimensões formativas? Que mudanças é preciso introduzir nas escolas para que elas se assumam como lugares de formação? (p. 30)

Partir do reconhecimento da escola como lócus privilegiado da formação continuada tem várias implicações. Trata-se de trabalhar com o corpo docente de uma determinada instituição favorecendo processos coletivos de reflexão e intervenção na prática pedagógica concreta, oferecendo espaços e tempos institucionalizados de encontro, criando sistemas de estímulo à sistematização das práticas pedagógicas dos/as professores/as e à sua socialização, e ressituando o trabalho de supervisão/orientação pedagógica nessa perspectiva.

A formação continuada, portanto, não pode ser concebida como um meio de acumulação (de cursos, palestras, seminários etc.) de conhecimentos ou de técnicas, e sim mediante um trabalho de reflexividade crítica sobre conhecimentos e práticas, de (re) construção permanente de uma identidade pessoal e profissional. É nessa perspectiva que acredito ser necessário pensar os processos de formação continuada de professores/as como multiplicadores de educação em direitos humanos e, a partir dela, incorporar diferentes estratégias pedagógicas, tanto presenciais quanto a distância.

\section{Formação continuada de professores/as e educação em direitos humanos}

Tendo presentes os aspectos já assinalados, destacarei alguns componentes que considero articuladores de processos de formação continuada de professores/as como agentes multiplicadores da educação em direitos humanos.

Em primeiro lugar, gostaria de ressaltar o que considero que deve ser evitado, porque educar em direitos humanos, na minha perspectiva, não significa: o desenvolvimento de uma série de atividades esporádicas sobre temas relacionados com os direitos humanos, sem articulação entre elas; a mera realização de campanhas sobre temas específicos; um conteúdo introduzido em algumas disciplinas e áreas curriculares; toda e qualquer formação em valores; a mera aquisição de algumas noções sobre a Declaração Universal dos Direitos Humanos e outros documentos referenciais para a área.

$\mathrm{Na}$ perspectiva que assumo, a educação em direitos humanos deve ser introduzida como um eixo orientador do projeto político-pedagógico de cada escola e ser objeto de uma reflexão coletiva e de todo o corpo docente, com a finalidade de promover sua incorporação em todas as áreas curriculares e nos diferentes componentes da dinâmica escolar, tais como as relações entre os diferentes sujeitos nela implicados - professores, alunos, funcionários, pais de alunos e agentes comunitários -, assim como as questões relativas aos processos avaliativos, à disciplina e aos conflitos presentes na escola, às relações com a comunidade etc.

A perspectiva da educação em direitos humanos que assumo está orientada a promover um compromisso existencial com a incorporação dos direitos humanos nas nossas vidas e práticas cotidianas. Não pode ser reduzida a uma dimensão meramente cognitiva, sem negar a importância da aquisição de um corpo de conhecimentos atualizado sobre essa temática. Nesse sentido, as estratégias metodológicas a ser utilizadas têm de ser coerentes com uma visão contextualizada e histórico-crítica do papel dos direitos humanos e do sentido da educação neste âmbito: formar sujeitos de direito, empoderar os grupos socialmente vulneráveis e excluídos e resgatar a memória histórica da luta pelos direitos humanos na nossa sociedade.

Sendo assim, a primeira pergunta que temos de nos fazer é se as estratégias pedagógicas que privilegiamos estão favorecendo caminhar nessa direção e quais são os aspectos que consideramos mais em sintonia com essa orientação.

É bastante comum que afirmemos que queremos formar sujeitos de direito e colaborar para a trans- 
formação social e, no entanto, do ponto de vista pedagógico, utilizamos fundamentalmente estratégias centradas no ensino frontal, isto é, exposições verbais ou mediáticas, quando muito introduzindo espaços de diálogo com expositores ou membros de mesas-redondas. Esse tipo de estratégia atua fundamentalmente no plano cognitivo, quando muito oferece informações, ideias e conceitos atualizados, mas não leva em consideração as histórias de vida e as experiências dos participantes e colabora pouco para a mudança de atitudes, comportamentos e mentalidades. Em geral, no melhor dos casos, propicia espaços de sensibilização e motivação para as questões de direitos humanos, mas seu caráter propriamente formativo é muito frágil.

A perspectiva anteriormente assinalada supõe a realização de processos formativos. A palavra processo é fundamental. Exige uma série de atividades articuladas e desenvolvidas em um determinado período de tempo.

Outra característica desses processos orientados pela concepção explicitada é o papel ativo de todos/ as os/as que deles participam. No que diz respeito aos temas a ser trabalhados, eles devem ser definidos tendo-se presente as características e interesses de cada grupo, mas sempre situando as questões abordadas num contexto social amplo e em relação à problemática e aos conceitos fundamentais relacionados com os direitos humanos. Além disso, é importante mobilizar diferentes dimensões presentes nos processos de ensino-aprendizagem, tais como: ver, saber, celebrar, sistematizar, comprometer-se e socializar. Essas dimensões são concebidas de maneira integrada e inter-relacionada. $\mathrm{O}$ ver refere-se à análise da realidade; o saber, aos conhecimentos específicos relacionados ao tema desenvolvido; o celebrar, à apropriação do trabalhado, utilizando diferentes linguagens, como simulações, dramatizações, músicas, elaboração de vídeos etc. A sistematização supõe a construção coletiva que sintetiza os aspectos mais significativos assumidos por todo o grupo; e o comprometer-se, a identificação de atitudes e ações a serem realizadas. A socialização da experiência vivida no contexto em que se atua constitui a etapa final do processo. Em todo ele, o papel do/a dinamizador/a, do/a professor/a é fundamental.

A utilização de metodologias ativas e participativas, o emprego de diferentes linguagens, a promoção do diálogo entre diversos saberes são componentes presentes ao longo de todo o processo, que deve ter como referência fundamental a realidade social e as experiências dos participantes. Especial atenção deve ser dada aos relatos de histórias de vida relacionadas às violações ou à defesa dos direitos humanos, apresentadas pelos próprios participantes, por meio de entrevistas realizadas com determinadas pessoas indicadas pelo grupo, matérias de jornais ou informes de outros meios de comunicação.

Trata-se, portanto, de transformar mentalidades, atitudes, comportamentos, dinâmicas organizacionais e práticas cotidianas dos diferentes atores, individuais e coletivos, e das organizações sociais e educativas. Para a construção de agentes multiplicadores é necessário favorecer processos que promovam um compromisso existencial com os direitos humanos. Para tal, é necessário educar em direitos humanos, isto é, propiciar experiências em que se vivenciem os direitos humanos.

\section{Considerações finais}

A promoção da formação de professores e professoras como agentes multiplicadores/as da educação em direitos humanos, na perspectiva adotada neste trabalho, supõe privilegiar processos de formação continuada em que se assume a escola como lócus privilegiado. É mediante a reflexão coletiva dos/as educadores/as, do diálogo entre a teoria e a prática, da busca conjunta da construção de práticas educativas coerentes com a construção de sociedades humanas e democráticas que se vão constituindo sujeitos, professores/as, existencialmente comprometidos/as com a afirmação dos direitos humanos nas nossas escolas e na sociedade em geral.

A perspectiva da educação em direitos humanos confronta políticas educativas centradas em aspectos meramente operacionais do processo educativo, que se voltam quase que exclusivamente para a dimensão cognitiva da educação e têm como horizonte a inserção na sociedade do mercado e do consumo. A educação em direitos humanos promove uma visão crítica sobre a realidade em que vivemos e o compromisso com sua transformação, tendo por base a construção de uma sociedade mais igualitária e equitativa e a construção de uma cultura dos direitos humanos que penetre todos os âmbitos sociais. 


\title{
Referências
}

BRASIL. Secretaria Especial dos Direitos Humanos. Comitê Nacional de Educação em Direitos Humanos. Plano Nacional de Educação em Direitos Humanos. Brasília, 2003. . Secretaria Especial dos Direitos Humanos. Plano Nacional de Educação em Direitos Humanos, Brasília, 2006. . Ministério da Educação. Conselho Nacional de Educação. Diretrizes Nacionais para a Educação em Direitos Humanos. Brasília: Diário Oficial da União, 30 de maio de 2012.

FRITZSCHE, P. K. O que significa educação em direitos humanos. 15 teses. In: GIORGI, V. e SEBERICH, M.
(Eds.). Perspectivas internacionais em educação em direitos humanos. Gütersloh: Bertelsmann Foundation Publishers, 2004.

HUNT, Lynn. A invenção dos Direitos Humanos. São Paulo: Companhia das Letras, 2009.

NÓVOA. A. Concepções e práticas da formação contínua dos professores. In: NÓVOA. A. (Org.). Formação contínua de professores: realidade e perspectivas. Aveiro: Universidade de Aveiro, 1991.

ONU. Assembleia Geral. Programa Mundial para a Educação em Direitos Humanos, 2008.

\section{Profesores: multiplicadores de educación en derechos humanos}

\section{Resumen}

Los derechos humanos constituyen uno de los ejes centrales de la problemática de las sociedades contemporáneas. Para su afirmación, la educación en derechos humanos viene desarrollándose con cada vez más fuerza en Brasil, del punto de vista normativo y de las políticas públicas, así como de las actividades promovidas por las organizaciones de la sociedad civil. Sin embargo, es posible decir que todavía es frágil y poco frecuente la discusión y reflexión sobre el sentido de la educación en derechos humanos en las instituciones de enseñanza. El presente trabajo defiende la tesis que la formación continuada de educadores es un espacio privilegiado para la incorporación de la educación en derechos humanos en nuestras escuelas, así como para la formación de educadores como agentes multiplicadores y comprometidos con los derechos humanos en el ámbito educativo y de la sociedad en su globalidad. Está organizado en tres partes que desarrollan los siguientes aspectos: el sentido de la educación en derechos humanos, la concepción que adoptamos de formación continuada y las principales características que debe tener una educación en derechos humanos orientada a la formación de educadores multiplicadores de esta perspectiva.

Palabras clave: educación en derechos humanos, formación continuada de educadores, agentes multiplicadores de derechos humanos.

\section{Educators: multipliers of human rights education}

\begin{abstract}
Human rights play a central role in the problems that contemporary societies face. In order to assert such rights, human rights education has strongly developed within Brazil in recent years. Notable developments have taken place in law, public policy and activities promoted by civil organizations regarding the issue. However, it is perceivable that discussions and reflections on human rights in our schools are still fragile and rare. This work defends the thesis that providing continuing education to professional educators is a viable strategy regarding the incorporation of this subject material into the school curriculum. Consequently, educators would function as committed agents of multiplication, not only in the school environment, but also within society as a whole. The paper, structured in three parts, conveys the following aspects: the meaning of human rights education; the conception we have adopted into this continuing education curriculum for educators; as well as the main characteristics this must contain in order to mobilize teachers into becoming multipliers of human rights education.
\end{abstract}

Key words: human rights education, continuing education for educators, agents of multiplication of human rights education.

Data de recebimento do artigo: 13/5/2013

Data de aprovação do artigo: 20/12/2013 